\title{
Long-term follow-up after surgical treatment of obstructive sleep apnoea by maxillomandibular advancement
}

\author{
R. Conradt*, W. Hochban**, U. Brandenburg*, J. Heitmann*, J.H. Peter*
}

\begin{abstract}
Long-term follow-up after surgical treatment of obstructive sleep apnoea by maxillomandibular advancement. R. Conradt, W. Hochban, U. Brandenburg, J. Heitmann, J.H. Peter. (C)ERS Journals Ltd 1997.

ABSTRACT: Obstructive sleep apnoea (OSA) is a common disorder with potentially serious consequences. If maxillary and mandibular deficiency, often in combination with a narrow posterior airway space is present, therapy of OSA by maxillomandibular osteotomy is possible. However, long-term follow-up of patients undergoing these procedures is lacking.

We present the results of 15 OSA patients (1 female and 14 males), who underwent maxillomandibular advancement surgery with a follow-up of at least 2 yrs. Polysomnography was performed before surgery, after 6-12 weeks, and 1 and 2 yrs postoperatively.

Mean apnoea/hypopnoea index (AHI) decreased from 51.4 events $h^{-1}$ before therapy to 5.0 events $\cdot h^{-1} 6$ weeks postoperatively, and was 8.5 events $\cdot h^{-1}$ after 2 yrs. Oxygen saturation significantly increased following surgery. After 2 yrs, the AHI was $<10$ events $\cdot h^{-1}$ in 12 out of 15 subjects. No significant changes were found comparing the 6-12 weeks versus the 2 year follow-up data. The significant increase in stage 3/4 non-rapid eye movement (NREM) sleep and decrease in stage 1 NREM sleep, indicative of the restoration of normal physiological sleep structure, persisted in 14 of the 15 subjects 2 yrs postoperatively. Three patients, however, did not show satisfactory improvement 2 yrs postoperatively; two showed obstructive and one central respiratory events.

This study demonstrates that maxillomandibular advancement is successful in a high percentage of patients carefully selected by cephalometric and polysomnographic investigation. Postoperative success has proved to be stable over a period of 2 yrs. Further preoperative evaluation seems necessary in patients with predominantly mixed or central apnoeas.
\end{abstract}

Eur Respir J., 1997; 10: 123-128.

Obstructive sleep apnoea (OSA) is one of the most common sleep disorders [1]. In patients with OSA, a fall in muscle tone in the striated muscles of the upper airway during sleep is critical in the development of complete (apnoea) or partial (hypopnoea, snoring) upper airway obstruction. However, the facial skeleton and the attachments of the suprahyoid, lingual and velopharyngeal muscular systems to the bony structures of the face are also important pathogenetic factors involved in the aetiology of upper airway obstruction. Therefore, pharyngeal obstruction is commonly found in patients with retrognathia or a dolichofacial appearance.

In 1981, Sullivan et al. [2] successfully introduced nasal continuous positive airway pressure (nCPAP) as a therapy for upper airway obstruction during sleep. Put simply, this form of treatment provides a constant pressure of air, which acts as a pneumatic splint within the upper airway, thus preventing its collapse during sleep. However, to maintain successful treatment, nCPAP must be used every night for life [3, 4], an option which does not appeal to all patients, especially those who are younger or have milder forms of OSA.

The first attempts at surgically treating OSA predate the introduction of nCPAP $[5,6]$. Uvulopalatopharyngoplasty
*Schlafmedizinisches Labor, Medizinische Poliklinik, and **Klinik für Mund-, Kiefer-, Gesichtschirurgie, Philipps-Universität Marburg, Germany.

Correspondence: W. Hochban

Klinik für Mund-, Kiefer-, Gesichtschirurgie Georg-Voigt-Str. 3

D-35033 Marburg

Germany

Keywords: Maxillimandibular advancement

sleep apnoea

surgical treatment

Received: September 111995

Accepted after revision April 151996

This study has been supported in part by Deutsche Forschungsgemeinschaft DFG.
(UPPP) has been widely used and remains a common treatment option in some centres. This surgical procedure was first described by IKEMATSU [7] in 1964, exclusively as a treatment to abolish the noise of snoring. In 1981, FuJITA et al. [8] described UPPP as a means of treating OSA. Since then, the operative technique of UPPP has been modified several times [9-11] but, despite such modifications, UPPP often only led to a reduction in snoring, while the pharyngeal obstruction and the resulting sleep fragmentation of OSA remained. Furthermore, many long-term studies of UPPP treatment for OSA have shown a fall in success rates with the passage of time [12, 13].

Craniofacial abnormalities in patients with OSA are common. The cephalometric examination $[14,15]$ of 540 patients with confirmed OSA revealed craniofacial abnormalities (in particular retrognathia and/or dolichofacial bony structure with accompanying pharyngeal narrowing) in about $40 \%$. Within this "subgroup" of patients with OSA, surgical treatment by facial osteotomies may be considered as a possible solution. In 1979, the successful treatment of three patients with OSA and mandibular retrognathia by mandibular advancement was described [16]. Simultaneous maxillary and mandibular advancement 
for the treatment of sleep-related breathing disorders (SRBD) was reported in 1983 [17]. RILEY and co-workers [18-21] then further developed the surgical treatment of patients with OSA by maxillary and mandibular osteotomy. Despite encouraging early postoperative results in selected patients, no studies describing postsurgical follow-up over a period of more than 1 year have been published, thus raising important questions and concerns regarding the long-term success of this form of treatment.

This study reports results in 15 such patients, diagnosed as having OSA, then treated surgically with maxillomandibular advancement, using the operative technique described previously by HochBAn et al. [22]. These patients were followed-up with repeat polysomnographic assessment at 6-12 weeks, and then every year postoperatively. We report the follow-up data 6-12 weeks and 2 years postoperatively.

\section{Methods}

\section{Selection of patients and sleep laboratory examinations}

Patients were recruited from the Marburg Sleep Laboratory, between 1989 and 1992. In this time, 540 patients who were diagnosed as having OSA underwent cephalometric evaluation (see below). Of these patients, 210 were offered maxillomandibular advancement surgery, as a treatment option, because of measured craniofacial abnormalities. Out of the 210 patients, 15 patients preferred surgical treatment over lifelong nCPAP-therapy, and the others decided to continue receiving nCPAP. The 15 patients ( 1 female and 14 males) treated by maxillomandibular advancement surgery have now been followed for a minimum of 2 yrs postoperatively, forming the basis of this report. The mean age $( \pm \mathrm{SD})$ of the subjects was 44-12 yrs, and the mean body mass index (BMI $\pm \mathrm{SD}$ ) was $28.3 \pm 3.4 \mathrm{~kg} \cdot \mathrm{m}^{-2}$ for the group. A comprehensive medical history, with particular attention to symptoms of excessive daytime sleepiness and cardiac disease, was obtained from each patient. All patients underwent a complete physical examination at initial assessment. Initial investigations included detailed overnight cardiorespiratory polysomnography, measuring the following parameters: electroencephalogram (EEG) (C3/A2 and $\mathrm{Cz} / \mathrm{O} 2$ of the 10-20 international electrode placement system); electrooculogram (EOG); chin (genioglossus) and leg (anterior tibialis) electromyogram (EMG); and electrocardiogram (ECG) (modified V2 lead). Airflow was monitored by a nasal thermistor, and an uncalibrated inductive respiratory plethysmograph (Respitrace TM; Stimotron, Wendelstein, Germany) monitored rib cage and abdominal wall movements. Respiratory sounds were recorded via a microphone placed over the anterior surface of the neck (Zentrales Entwicklungslabor fur Elektronik, Marburg, Germany). Oxygen saturation was continuously recorded by a pulse oximeter (Biox 3700TM; Ohmeda, Erlangen, Germany).

Polysomnographic data were recorded continuously on an 8 channel polygraph (UD210; Madaus-Schwarzer, München, Germany) at a paper speed of $10 \mathrm{~mm} \cdot \mathrm{s}^{-1}$. Respiratory parameters were also recorded continuously on a second polygraph at a paper speed of $1 \mathrm{~mm} \cdot \mathrm{s}^{-1}$. Sleep stage and wakefulness were scored visually from the polysomnographic records, in $30 \mathrm{~s}$ epochs, according to the criteria of RechtSCHAFFEN and Kales [23]. Total sleep time (TST) in minutes, sleep efficiency (SE) in percentage, and the percentages of time spent in each sleep stage (as a percentage of the TST) were determined. Arousals were scored according to the criteria of the American Sleep Disorders Association (ASDA) [24]. Respiratory parameters were also scored from the polygraph recordings, with each quantified respiratory disturbance requiring a minimum duration of $10 \mathrm{~s}$ to be scored. Apnoeas were scored by definition [25]. Furthermore, an apnoea was scored as obstructive if respiratory efforts continued during the cessation of nasal airflow. A lack of respiratory efforts characterized a central apnoea. Obstructive hypopnoeas were scored if airflow and/or thoracic and abdominal respiratory excursions were reduced in comparison to normal respiration, and if this respiratory event was associated with recording of snoring sounds and terminated by an arousal. Hypopnoeas were scored as central if breathing effort was reduced, oxygen saturation dropped by more than $3 \%$ in association with a pattern of periodic breathing, and if an arousal took place during the hyperventilation phase following periodic breathing. From the total number of apnoeas and hypopnoeas, the apnoea index (AI) and hypopnoea index (HI) (average numbers of each events per hour of sleep time) were calculated. The apnoea hypopnoea index (AHI) was calculated by adding AI and HI. When the initial polysomnographic assessment confirmed a diagnosis of sleep apnoea, detailed cephalometric measurements (see below) were made and treatment options, including surgery and nCPAP, were discussed with the patient.

\section{Preoperotive management of SRBD}

Prior to surgery, 12 of the 15 patients had undertaken nCPAP therapy for at least 3 months, aiming to improve some of the pathophysiological sequelae of OSA (daytime sleepiness, upper airway oedema, etc.), thereby lowering the operative risks faced by the patient. Prior to commencing nCPAP, the individual nCPAP pressure required by each patient was titrated during a further two nights of study in the sleep laboratory. During nCPAP pressure titration, nocturnal recording was performed without EEG recordings. Additionally, instead of nasal airflow, the nCPAP mask pressure applied to the patient was measured. Two young patients steadfastly objected to any treatment attempt with nCPAP. The remaining patient wore a dental appliance preoperatively as therapy for his SRBD.

\section{Cephalometric examination}

Cephalometric examination was carried out using standardized recording techniques [26], with remote radiographic tracing of the viscerocranium in profile view for the measurement of vertical and sagittal dimensions. The lateral radiograph was performed using a $4 \mathrm{~m}$ distance between focal point and radiographic film. The distance between the patient and the radiographic film was kept as small as possible. This method minimizes magnification of the cephalometric measuring distance due to projection effects. Part of the cephalometric data (fig. 1) used as indicators for surgery were the angles 


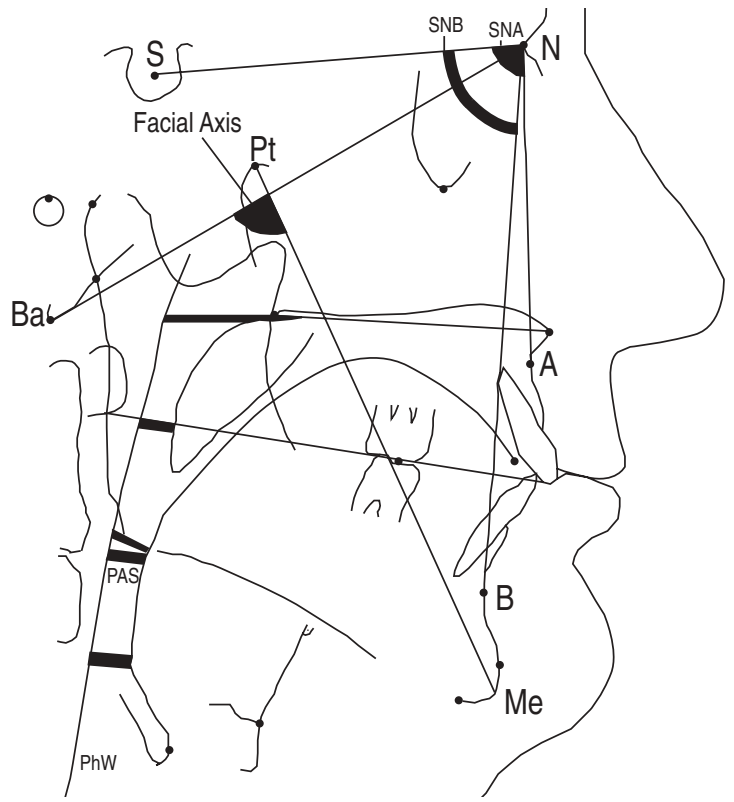

Fig. 1. - Cephalometric tracing (extract) for evaluation of craniofacial deformities and pharyngeal dimensions in patients with obstructive sleep apnoea. SNA: angle between sella (S), nasion (N) and subspinale point-A; SNB: angle between sella, nasion and supramentale point-B; Facial axis: angle Ba (skull base) - N/Pt (pterygoid) - Me (menton); PAS: posterior airway space, measured at different levels; PhW: pharyngeal wall.

SNA (angle between sella, nasion and subspinale pointA) and SNB (angle between sella, nasion and supramentale point-B). SNA and SNB served as a measure of the sagittal relationship of the mandible or maxilla. Facial axis (angle between skull base of nasion and ptgerygoid fossa to menton) served for a measure of sagittal as well as vertical dimension. RILEY and co-workers [27, 28] introduced the cephalometric measurement of the posterior airway space (PAS), the distance between the base of the tongue and the posterior pharyngeal wall, as a measurement for the recognition of pharyngeal obstruction. PAS values should be determined by means of remote radiographic tracings at different levels. PAS values correlate highly with three dimensional measurements of the pharynx obtained from computer tomograms.

\section{Indication for surgery}

A surgical treatment option as an alternative to nCPAP was offered to all patients with subjective symptoms of excessive daytime sleepiness, an AHI greater than 20 events $\cdot \mathrm{h}^{-1}$ (as measured from overnight polysomnography), and certain craniofacial characteristics. These consisted in pharyngeal narrowing in the basal lingual area with retrognathia, for instance if PAS at the level of the mandibular base was less than $11 \mathrm{~mm}$ and the SNB measured less than $77^{\circ}$. Usually, pharyngeal narrowing was found in combination with retrognathia or a dolichofacial appearance $[14,15]$. Because of increased perioperative risks, patients over 70 yrs of age were excluded. Other contraindications to surgery included medical and psychiatric co-morbidity, morbid obesity (BMI >32 $\mathrm{kg} \cdot \mathrm{m}^{-2}$ ), alcohol or drug abuse. Patients had to fully understand the surgical procedure, be aware of other treatment avenues and provide written consent to surgery.

\section{Surgical procedure}

Patients underwent simultaneous maxillomandibular advancement. Current indications are that an advancement of $10 \mathrm{~mm}$ of both maxilla and mandible is considered to be adequate [22, 29]. In eugnathic patients, the bite would remain unchanged, whilst in patients with dysgnathias, abnormalities of bite were corrected simultaneously. Operative mandibular advancement is effected by a bilateral retromolar sagittal osteotomy; maxillary advancement is achieved by osteotomy at the Le Fort-I level. Bone interpositions were not necessary. The maxilla was fixed in the new position using miniplates, while bicortical miniscrews held the mandible in its new position.

\section{Postoperative assessment}

Each of the 15 patients underwent detailed cardio-respiratory polysomnography (as detailed above) at 6-12 weeks postoperatively, and then again at 2 years follow-up.

\section{Statistical analyses}

Analysis of variance (ANOVA) for repeated measures was used for statistical analysis of dependent variables. Multiple nonindependent testing was taken into account by $\alpha$-adjustment. Differences between variables before treatment and after surgery were tested. Significant results from ANOVA were further assessed by the Scheffé method. Statistical significance was assumed for a pvalue of less than 0.05 . All results are shown as mean \pm SD.

\section{Results}

No significant change in BMI occurred during the study period. The results of respiratory events during sleep are summarized in tables 1 and 2. Because therapeutic sleep studies using nCPAP were performed without EEG measurement, respiratory events during these studies could not be compared statistically with other studies. Nevertheless, figure 2 shows almost complete correction of SRBD, with the AHI decreased both during nCPAP therapy and following surgery. Arterial oxygen saturation $\left(\mathrm{Sa}_{\mathrm{a}} \mathrm{O}_{2}\right)$ during sleep showed a similar marked improvement with nCPAP therapy and following surgery. The time periods spent with an $\mathrm{Sa}, \mathrm{O}_{2}$ less than $90 \%$ were significantly decreased under therapy. Because $\mathrm{Sa}_{2} \mathrm{O}_{2}$ values of less than $80 \%$ were not recorded during therapeutic studies, comparison of $\mathrm{Sa}, \mathrm{O}_{2}$ results using ANOVA was not possible.

Although a slight rise in AHI was observed in many patients (12 out of 15) during the 2 year follow-up period, the increase was not statistically significant compared to the immediate postoperative control. In three patients, the number of respiratory disturbances during sleep reached borderline values. Two of the three patients had predominantly obstructive respiratory events. One of them showed an AHI before treatment of 57.5 events $\cdot \mathrm{h}^{-1}$, and, after initial postsurgical reduction below 10 events $\cdot h^{-1}, 2 \mathrm{yrs}$ after surgery, the AHI rose again to 
Table 1. - Pre- and postoperative respiratory data during sleep

\begin{tabular}{|c|c|c|c|c|c|c|c|}
\hline & Pre-op & $\begin{array}{c}\text { 6-12 } \\
\text { wks } \\
\text { post-op }\end{array}$ & $\begin{array}{l}\text { p-value } \\
6-12 \text { wks } \\
\text { post-op } \\
\text { to pre-op }\end{array}$ & $\begin{array}{c}2 \mathrm{yrs} \\
\text { post-op }\end{array}$ & $\begin{array}{l}\text { p-value } \\
2 \text { yrs } \\
\text { post-op } \\
\text { to pre-op }\end{array}$ & $\begin{array}{l}\text { p-value } 2 \text { yrs } \\
\text { post-op } \\
\text { to } 6-12 \text { wks } \\
\text { post-op }\end{array}$ & nCPAP \\
\hline AHI events $\cdot h^{-1}$ & $\begin{array}{l}51.4 \\
(16.9)\end{array}$ & $\begin{array}{c}5.0 \\
(5.8)\end{array}$ & $<0.05$ & $\begin{array}{l}8.5 \\
(9.4)\end{array}$ & $<0.05$ & NS & $\begin{array}{c}3.9 \\
(5.3)\end{array}$ \\
\hline AI events $\cdot h^{-1}$ & $\begin{array}{c}33.6 \\
(21.4)\end{array}$ & $\begin{array}{c}2.3 \\
(4.1)\end{array}$ & $<0.05$ & $\begin{array}{l}1.3 \\
(2.3)\end{array}$ & $<0.05$ & NS & $\begin{array}{c}1.0 \\
(2.9)\end{array}$ \\
\hline HI events $\cdot h^{-1}$ & $\begin{array}{c}17.8 \\
(15.0)\end{array}$ & $\begin{array}{l}2.8 \\
(2.8)\end{array}$ & $<0.05$ & $\begin{array}{c}7.3 \\
(8.3)\end{array}$ & $<0.05$ & NS & $\begin{array}{c}2.9 \\
(3.7)\end{array}$ \\
\hline $\begin{array}{l}\% \mathrm{TST} \\
<90 \% \mathrm{Sa}_{2} \mathrm{O}_{2}\end{array}$ & $\begin{array}{c}12.6 \\
(14.6)\end{array}$ & $\begin{array}{c}0.4 \\
(1.1)\end{array}$ & $<0.05$ & $\begin{array}{c}2.3 \\
(4.1)\end{array}$ & $<0.05$ & NS & $\begin{array}{c}0.0 \\
(0.0)\end{array}$ \\
\hline
\end{tabular}

Values are presented as mean, and SD in parenthesis. pre-op: preoperative; post-op: postoperative; AHI: number of apnoeas and hypopnoeas per hour of sleep; AI: number of apnoeas per hour of sleep; HI: number of hypopnoeas per hour of sleep; $\mathrm{Sa}_{\mathrm{a}} \mathrm{O}_{2}$ : arterial oxygen saturation; \% TST $<90 \% \mathrm{Sa}_{2} \mathrm{O}_{2}$ : percentage of total sleep time spent with less than $90 \% \mathrm{Sa}, \mathrm{O}_{2}$. NS: not significant; nCPAP: nasal continuous positive airway pressure.

Table 2. - Number of obstructive and central respiratory events during sleep

\begin{tabular}{ccccc}
\hline & Pre-op & $\begin{array}{c}\text { 6-12 weeks } \\
\text { post-op }\end{array}$ & $\begin{array}{c}2 \text { yrs } \\
\text { post-op }\end{array}$ & nCPAP \\
\hline Obstructive & 187.3 & 7.8 & 6.1 & 3.1 \\
apnoeas n & $(150.3)$ & $(20.8)$ & $(12.1)$ & $(7.4)$ \\
Mixed apnoeas & 31.9 & 1.5 & 0.4 & 0.8 \\
n & $(55.7)$ & $(3.1)$ & $(1.3)$ & $(1.6)$ \\
Obstructive & 123.7 & 15.1 & 30.7 & 12.3 \\
hypopnoeas n & $(102.2)$ & $(16.4)$ & $(28.8)$ & $(19.0)$ \\
Central apnoeas & 1.0 & 5.2 & 1.2 & 4.1 \\
n & $(2.6)$ & $(9.9)$ & $(2.8)$ & $(13.5)$ \\
Central & 0.0 & 2.4 & 15.1 & 4.8 \\
hypopnoeas n & $(0.0)$ & $(3.5)$ & $(50.8)$ & $(13.7)$ \\
\hline
\end{tabular}

Values are presented as mean, and SD in parenthesis. Pre-op: preoperative; post-op: post operative.

12.8 events $\cdot \mathrm{h}^{-1}$. The second patient presented with an AHI of 67.3 events $\cdot h^{-1}$, mostly very long obstructive apnoeas associated with significant falls in $\mathrm{Sa}_{2} \mathrm{O}_{2}$. In this patient, the mandible was advanced by $14 \mathrm{~mm}$, but the maxilla was advanced by only $4 \mathrm{~mm}$ because of a marked dysgnathia, otherwise a bone interposition in the mandible would have been necessary. Approximately 3 months

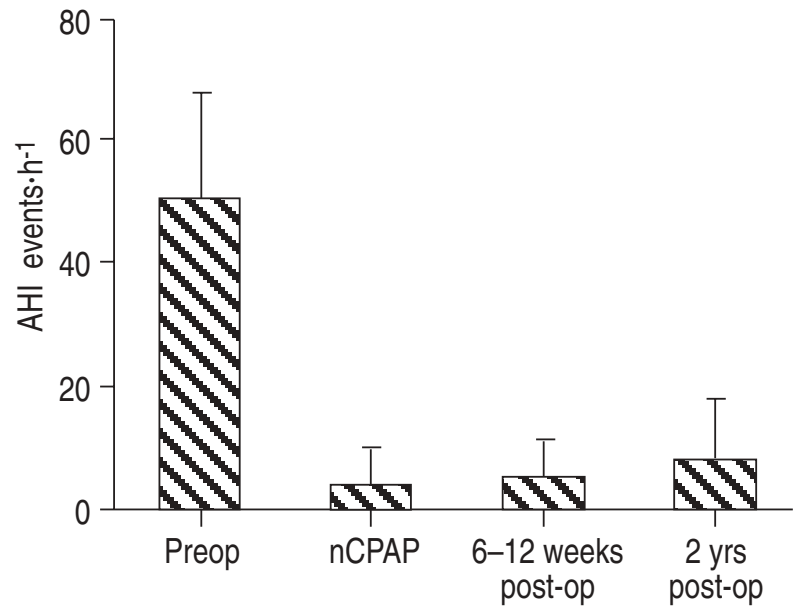

Fig. 2. - Apnoea-hypopnoea index (AHI) preoperative, during nCPAP therapy, and 6-12 weeks and 2 yrs after surgery. Values are presented as mean and SD. Pre-op: preoperative; post-op: postoperative; nCPAP: nasal continuous positive airway pressure.

after this facial skeleton osteotomy, this patient underwent further surgical lifting of the soft palate allowing an additional straightening of the velopharyngeal muscular system. All these measures resulted in insufficient

Table 3. - Pre- and postoperative polysomnographic results for all subjects

\begin{tabular}{|c|c|c|c|c|c|c|}
\hline & Pre-op & $\begin{array}{c}\text { 6-12 wks } \\
\text { post-op }\end{array}$ & $\begin{array}{l}\text { p-value } \\
6-12 \text { wks } \\
\text { post-op } \\
\text { to pre-op }\end{array}$ & $\begin{array}{c}2 \mathrm{yrs} \\
\text { post-op }\end{array}$ & $\begin{array}{c}\text { p-value } 2 \text { yrs } \\
\text { post-op } \\
\text { to pre-op }\end{array}$ & $\begin{array}{c}\text { p-value } \\
2 \text { yrs post-op } \\
\text { to } 6-12 \mathrm{wks} \\
\text { post-op }\end{array}$ \\
\hline TST min & $\begin{array}{c}424.1 \\
(54.0)\end{array}$ & $\begin{array}{l}400.3 \\
(45.6)\end{array}$ & NS & $\begin{array}{l}371.8 \\
(44.0)\end{array}$ & NS & NS \\
\hline SE \% & $\begin{array}{l}89.5 \\
(7.3)\end{array}$ & $\begin{array}{l}89.2 \\
(7.0)\end{array}$ & NS & $\begin{array}{l}88.8 \\
(6.1)\end{array}$ & NS & NS \\
\hline NREM1 \% & $\begin{array}{l}12.8 \\
(6.8)\end{array}$ & $\begin{array}{c}8.9 \\
(4.4)\end{array}$ & $<0.05$ & $\begin{array}{c}8.2 \\
(5.1)\end{array}$ & $<0.05$ & NS \\
\hline NREM2 \% & $\begin{array}{c}60.2 \\
(11.1)\end{array}$ & $\begin{array}{l}51.3 \\
(6.2)\end{array}$ & $<0.05$ & $\begin{array}{l}56.4 \\
(6.7)\end{array}$ & $<0.05$ & NS \\
\hline NREM $3 / 4 \%$ & $\begin{array}{c}9.3 \\
(5.3)\end{array}$ & $\begin{array}{l}16.1 \\
(3.9)\end{array}$ & $<0.05$ & $\begin{array}{l}15.6 \\
(4.8)\end{array}$ & $<0.05$ & NS \\
\hline REM \% & $\begin{array}{l}16.4 \\
(6.1)\end{array}$ & $\begin{array}{l}20.4 \\
(4.3)\end{array}$ & $<0.05$ & $\begin{array}{l}20.4 \\
(4.7)\end{array}$ & $<0.05$ & NS \\
\hline
\end{tabular}

Values are presented as mean, and SD in parenthesis. pre-op: preoperative; post-op: postoperative; TST: total sleep time; SE: sleep efficiency; NREM1 and NREM2: stage 1 and 2 non-rapid eye movement sleep, respectively; REM: rapid eye movement sleep; NS: not significant. 
reduction in AHI to only 20 events $\cdot \mathrm{h}^{-1}$, obviously due to the minor advancement of the maxilla. Two years after surgery, the AHI rose again to 29 events $\cdot \mathrm{h}^{-1}$. The third patient showed predominantly central apnoeas, the obstructive apnoeas disappeared, the central apnoeas remained, with an increase at the 2 year follow-up (AHI before treatment: 65.6 events $\cdot \mathrm{h}^{-1} ; 2$ yrs after surgery: 31.5 events $\left.\cdot \mathrm{h}^{-1}\right)$.

Obstructive apnoeas appeared only sporadically both in nCPAP and postoperative studies. Persisting respiratory abnormalities were mostly incomplete upper airway obstructions (table 2). Table 2 shows that nearly half of the persisting respiratory disturbances were central events. The results of EEG evaluation are summarized in table 3 . The overall quality of sleep improved markedly after surgery. A significant postoperative increase in stage 3/4 NREM sleep, together with a decrease in the proportion of stage 1 NREM sleep, suggested a restoration of a more normal physiological sleep architecture in 14 of the 15 patients. Both EEG and respiratory parameters remained stable throughout the 2 year postoperative follow-up period, showing no statistically significant variations.

\section{Discussion}

Comparison of pre- and postoperative polysomnography suggests a clear improvement in SRBD in nearly all patients following maxillomandibular advancement surgery. Obstructive apnoeas occurred only sporadically postoperatively. Two patients showed a pattern of central respiratory events 2 yrs after surgery. One of these patients had developed such abnormal control of breathing that, in retrospect, the indication for surgery must be re-evaluated as a mistake. Preoperatively, both patients showed mixed apnoeas during sleep, with long central and only very short obstructive components. Whether there is a causal connection between these events and the postoperative outcome is still unclear.

The proportions of slow-wave sleep and percentage of stage 1 NREM sleep best reflect sleep quality, and are closely associated with daytime alertness [30, 31]. A severe SRBD is frequently associated with a strong reduction of slow-wave sleep and an increase in stage 1 NREM sleep. In the patients presented here, the distribution of sleep stages was normal throughout the whole postoperative follow-up period. The alterations in the $\mathrm{Sa}, \mathrm{O}_{2}$ as well as the change in quantity of slowwave sleep both indicate the remaining obstructive respiratory events to be of little if any clinical relevance.

During maxillomandibular advancement, muscles, ligaments and tendons attached to the jaw were not loosened but equally advanced and straightened with the advancement of their bony origins. This results in a modification of pharyngeal and palatal muscles, as well as the lingual and suprahyoid muscles. Within the pharynx, a skeletal expansion and an enlargement of the pharyngeal soft tissue tube was achieved. Thus, the effectiveness of maxillomandibular advancement is most likely to be due to a combination of a change in tension in the suprahyoid and velopharyngeal muscles, even if the mechanical enlargement of the posterior airway space contributes to that effect.
This type of surgery is not indicated for central apnoeas or hypopnoeas, since the underlying pathophysiology is more likely to be related to abnormalities of chemoreceptor function and central control mechanisms than to obstruction of the upper airway. Therefore, prior to surgery, nocturnal assessment of respiratory and sleep parameters is essential for a proper evaluation of existing SRBD, prior to decisions being made regarding further therapeutic procedures. Full cardiorespiratory polysomnography allows a complete evaluation, to determine whether nocturnal respiratory disturbances are associated with upper airway obstruction or are central in nature. Short periods of treatment with "conservative" forms of therapy may also unmask co-existing central respiratory regulation disorders, the patient's periodic breathing pattern being revealed after the removal of pharyngeal obstruction during sleep.

In light of the present results, maxillomandibular surgery is not indicated if sleep breathing abnormalities persist after the removal of upper airway obstruction by nCPAP. In patients with purely obstructive sleep apnoea, however, operative treatment proved to be successful in all but one case. This exception was the patient whose maxilla was advanced by $4 \mathrm{~mm}$ only, because of extreme posterior displacement of the mandible. In this case, mandibular advancement was followed by a UPPP and a palatal advancement to lift the velopharyngeal muscles. Retrospectively, further maxillary advancement would probably have been a preferable option in this case. The extreme dysgnathia was the result of an untreated degenerative arthropathy of both the temporomandibular joints, present for 20 yrs, resulting in nearly complete destruction of the joints and the articulating processes. As the patient had no clinical symptoms, he refused the initial suggestion of joint reconstruction with osteochondral transplants. The correction of the maxillomandibular bite discrepancy resulted in a maxillary advancement of only $4 \mathrm{~mm}$. Subsequently, the AHI was reduced by approximately $50 \%$. After the persisting upper airway obstruction during sleep was localized to the level of the velopharynx, further measures (UPPP and advancement of palatal plate) resulted in a further reduction of AHI to 20 events $\cdot \mathrm{h}^{-1}$. This value had increased to 29 events $\cdot \mathrm{h}^{-1}$ at the 2 year control. The remaining SRBD were obstructive apnoeas associated with massive desaturations, with continuing severe sleep fragmentation. Because of the persisting abnormal SRBD, this patient recommenced nCPAP therapy.

With the exception of this one case, further surgical intervention, such as UPPP or chin advancement, was not necessary following primary mandibular and maxillary advancement surgery. Therefore, we recommend maxillomandibular advancement as the primary surgical treatment of choice in cephalometrically selected patients. UPPP, genioplasty etc. should be performed as secondary procedures if at all necessary. This is in contrast to the findings of other investigators [18-21].

Three patients with symptoms related to difficulty with sleep onset and sleep maintenance felt subjectively disturbed by nCPAP therapy. These patients all benefited from maxillomandibular surgery and felt improved during the day, despite persisting non-breathing-related sleep fragmentation and a rather low sleep efficiency. 
Though many studies have shown that nCPAP therapy is highly accepted (by 35-80\% of users [32-34]) maxillomandibular advancement appears to be an effective and adequate alternative for those patients who do not want to tolerate lifelong nCPAP therapy, or for patients for whom nCPAP is not an optimal treatment due to anatomical abnormalities. While the stability of these initial postoperative results will need to be followed for a longer period, we are encouraged by our findings after 2 years of follow-up.

\section{References}

1. Young T, Palta M, Dempsey J, Skatrud J, Weber S, Badr S. The occurrence of sleep-disordered breathing among middle-aged adults. N Engl J Med 1993; 328: $1230-1235$.

2. Sullivan CE, Issa FG, Berthon-Jones M. Reversal of obstructive sleep apnoea by continuous positive airway pressure applied through the nares. Lancet 1981; i: 862-865.

3. McEvoy RD, Thornton AT. Treatment of obstructive sleep apnea syndrome with nasal continuous positive airway pressure. Sleep 1984; 7: 313-325.

4. Brandenburg U, Weiner H, Becker H, Mayer J, Peter $\mathrm{JH}$, von Wichert P. Hämodymamik und Schlafstruktur im Auslaßversuch nach nCPAP-Beatmungstherapie. Pneumlologie 1993; 47: 181-183.

5. Valero A, Alroy G. Hypoventilation in acquired micrognathia. Arch Intern Med 1965; 115: 307-310.

6. Kuhlo W, Doll E, Fran M. Erfolgreiche Behandlung des Pickwickian Syndrom durch eine Dauertracheal Kanüle. Dtsch Med Wschr 1969; 94: 1286-1290.

7. Ikematsu T. Study of snoring. Fourth report. Therapy J Jpn Otorhinolaryngol 1964; 64: 434-437.

8. Fujita S, Conway W, Zorick FJ, Roth T. Surgical correction of anatomical abnormalities in obstructive sleep apnea syndrome: uvulopalatopharyngoplasty. Orolaryngol Head Neck Surg 1981; 89: 923-934.

9. Fujita S. Surgical treatment of obstructive sleep apnea: UPPP and linguoplasty (laser midline glossectomy). In: Guilleminault C, Partinen M, eds Obstructive Sleep Apnea Syndrome. New York, Raven Press, 1990; pp. 129-151.

10. Crestinu JM. Intrapalatine resection (IPR) in the treatment of sleep apnea and snoring. Plast Reconstr Surg 1991; 87: 467-469.

11. O'Leary MJ Millman RP. Technical modifications of uvulopalatopharyngoplasty: the role of the palatopharyngeus. Laryngoscope 1991; 101: 1332-1335.

12. Burgess LP, Derderian SS, Morian GV, Gonzalez C, Zajtchuk JT. Postoperative risk following uvulopalatopharyngoplasty for obstructive sleep apnea. Otolaryngol Head Neck Surg 1992; 106: 81-86.

13. Larsson H, Carlsson-Nordlander B, Syanborg E. Longterm follow-up after UPPP for obstructive sleep apnea syndrome. Acta Otolaryngol (Stockh) 1991; 3: 582-590.

14. Hochban W. Das obstruktive Schlafapnoe-Syndrom: Diagnostik und Therapie unter Berücksichtigung kraniofazialer Anomalien. Berlin, Blackwell WissenschaftsVerlag, 1995

15. Hochban W, Brandenburg U. Morphology of the viscerocranium in obstructive sleep apnoea syndrome: cephalometric evaluation of 400 patients. J Cranio Max Fac Surg 1994; 22: 205-213.

16. Kuo PC, West RA, Bloomquist DS, McNeil RW. The effect of mandibular osteotomy in three patients with hypersomnia sleep apnea. Oral Surg Oral Med Oral Pathol 1979; 48: 385-392.

17. Wittig R, Wolford G, Conway W, et al. Mandibular advancement as a treatment of sleep apnea syndrome (Abstract). Sleep Res 1983, 12: 296.

18. Riley RW, Powell NB, Guilleminault C. Inferior mandibular osteotomy and hyoid myotomy suspension for obstructive sleep apnea: a review of 55 patients. $J$ Oral Maxillofac Surg 1989; 47: 159-164.

19. Riley RW, Powell NB, Guilleminault C. Maxillofacial surgery and obstructive sleep apnea: a review of 80 patients. Otolaryngol Head Neck Surg 1989; 101: 353-361.

20. Riley RW, Powell NB, Guilleminault C. Maxillary, mandibular, and hyoid advancement for treatment of obstructive sleep apnea: a review of 40 patients. $J$ Oral Maxillofac Surg 1990; 48: 20-26.

21. Powell NB, Riley RW, Guilleminault C. Maxillofacial surgery for obstructive sleep apnea. In: Guilleminault C, Partinen M, eds. Obstructive Sleep Apnea Syndrome. New York, Raven Press, 1990; pp. 153-182.

22. Hochban W, Brandenburg U, Peter IH. Surgical treatment of obstructive sleep apnea by maxillomandibular advancement. Sleep 1994; 17: 624-629.

23. Rechtschaffen A, Kales A. A manual of standardized terminology, techniques and scoring system for sleep stages of human subjects Washington, Public Health Service, US Government Printing Office, 1968.

24. American Sleep Disorders Association (ASDA) report. EEG arousal: scoring rules and examples. A preliminary report from the sleep disorders. Atlas task of the American Sleep Disorders Association. Sleep 1992; 2: 1-22.

25. Bornstein SK. Respiratory monitoring during sleep: polysomnography. In: Guilleminault $\mathrm{C}$, ed. Sleep and Waking Disorders: Indications and Techniques. New York, Addison and Wesley, 1982; p. 183.

26. Jacobson A, Caufield PW. Introduction to radiographic cephalometry. Philadelphia, Lea \& Febiger, 1985.

27. Riley RW, Powell NB, Guilleminault C. Cephalometric roentgenograms and computerized tomographic scans in obstructive sleep apnea (Letter to the Editor). Sleep 1986; 9: 514-515.

28. Riley RW, Powell NB, Guilleminault C. Current surgical concepts for treating obstructive sleep apnea syndrome. J Oral Maxillofac Surg 1987; 45: 149-157.

29. Waite PD, Wooten V. Maxillomandibular advancement surgery for obstructive sleep apnea. J Oral Maxillofac Surg 1990; 48: 770-771.

30. Guilleminault C, Partinen M, Quera-Salva A, Hayes B, Dement WC, Nino-Murcia G. Determinants of daytime sleepiness in obstructive sleep apnoea. Chest 1988; 94: 32-37.

31. Roehrs T, Zorick F, Witting R, Conway W, Roth T. Predictors of objective level of daytime sleepiness in patients with sleep-related breathing disorders. Chest 1989; 95: 1202-1206.

32. Stammnitz A, Becker H, Schneider H, Fus E, Peter $\mathrm{JH}$. Fortschritte in der nasalen Ventilationstherapie schlafbezogener Atmungsstörungen (SBAS). Wien Med Wochenschr 1994; 144: 83-87.

33. Kribbs NB, Pack AI, Kline LR, et al. Objective measurement of patterns of nasal CPAP use by patients with obstructive sleep apnea. Am Rev Respir Dis 1993; 147: 887-895.

34. Krieger J, Kurtz D. Objective measurement of compliance with nasal CPAP treatment for obstructive sleep apnea syndome. Eur Respir J 1988; 1: 436-438. 